\title{
OCENA ZWICHRZENIA SPRĘŻYSTEGO NA PODSTAWIE INTERAKCJI SYMETRYCZNYCH I ANTYSYMETRYCZNYCH STANÓW OBCIĄŻENIA
}

\begin{abstract}
Przedstawiono zagadnienie sprężystej utraty płaskiej postaci zginania stalowych belek o przekrojach dwuteowych bisymetrycznych, które są poddane jednokierunkowemu zginaniu względem osi większej bezwładności. Zaproponowano alternatywny w stosunku do konwencjonalnego sposób wyznaczenia wartości sprężystego momentu krytycznego zwichrzenia, przy dowolnym rozkładzie momentu zginającego wzdłuż osi pręta, bazujący na interakcji symetrycznej i antysymetrycznej postaci zwichrzenia. Zaproponowane podejście analityczne porównano z wynikami analiz numerycznych MES, na przykładzie swobodnie podpartej belki zginanej dwoma momentami podporowymi o różnym znaku i wartości oraz siłą skupioną w połowie rozpiętości belki.
\end{abstract}

Słowa kluczowe: dwuteownik stalowy, belka, zwichrzenie, LBA

\section{Wprowadzenie}

Właściwa ocena zagadnienia zwichrzenia stalowych belek o przekrojach dwuteowych bisymetrycznych jest bardzo istotna w projektowaniu zginanych elementów konstrukcji. Zarówno w literaturze zagranicznej jak i krajowej, m.in. [1-6] oraz wielu innych, można znaleźć wzory na moment krytyczny belki zginanej w postaci zarówno rozwiązań ścisłych jak i przybliżonych. Dotychczasowe, konwencjonalne propozycje rozwiązań przybliżonych, w przypadku belek z obciążeniem wywołującym zginanie o zmiennej wartości na długości pręta, bazują na zastosowaniu współczynników równoważnego stałego momentu, jako mnożnika do momentu krytycznego określonego przy założeniu pierwszej, symetrycznej postaci zwichrzenia. Założenie to przyjmuje się również w przypadku, gdy belka zginana jest obciążeniem o charakterze antysymetrycznym, któremu w praktyce towarzyszy pierwsza postać zwichrzenia będąca postacią antysymetryczną.

\footnotetext{
${ }^{1}$ Zbigniew Stachura, Politechnika Warszawska, al. Armii Ludowej 16, 00-637 Warszawa, tel.: +48 22234 6261, z.stachura@il.pw.edu.pl
} 
W pracy [2] zaproponowano alternatywny sposób oszacowania sprężystego momentu krytycznego zwichrzenia belki na podstawie interakcji symetrycznego i antysymetrycznego składnika momentu krytycznego. Rozpatrzono przypadek obciążenia momentów skupionych o różnej wartości, przyłożonych na końcach pręta. W niniejszym opracowaniu, zaproponowany w [2] sposób oszacowania momentu krytycznego uogólniono na przypadki dowolnego rozkładu wykresu momentu zginającego wzdłuż pręta. Na wybranym przykładzie obciążenia belki, zaproponowane podejście analityczne porównano $\mathrm{z}$ wynikami analiz numerycznych wykonanych przy użyciu programu LTBeamN [www.cticm.com].

\section{Sformułowanie analityczne dotyczące wyznaczenia wartości sprężystego momentu krytycznego zwichrzenia}

Sprężysty moment krytyczny zwichrzenia w odniesieniu do belki o przekroju dwuteowym bisymetrycznym, podpartej widełkowo i obciążonej w środku ścinania, można na podstawie rozwiązania liniowej teorii stateczności (LBA) aproksymować jak następuje:

$$
M_{c r}=C_{1} i_{C} \sqrt{N_{c r, z} N_{c r, T}}
$$

gdzie: $N_{c r, z}, N_{c r, T}$ - siły krytyczne przy sprężystym wyboczeniu względem osi głównej mniejszej bezwładności przekroju oraz przy wyboczeniu skrętnym:

$$
N_{c r, z}=\frac{\pi^{2} E I_{z}}{\left(k_{z} L\right)^{2}}, N_{c r, T}=\frac{1}{i_{C}^{2}}\left\{G I_{T}+\frac{\pi^{2} E I_{w}}{\left(k_{w} L\right)^{2}}\right\}, i_{C}^{2}=\frac{I_{y}+I_{z}}{A}
$$

$k_{z}, k_{w}$ - współczynniki długości wyboczeniowej zależne od warunków podparcia przekrojów końcowych pręta. Współczynnik $k_{z}$ jest związany z warunkami brzegowymi dotyczącymi swobody obrotu przekrojów końcowych względem osi głównej z-z, zaś współczynnik $k_{w}$ odnosi się do warunków brzegowych dotyczących deplanacji przekrojów końcowych przy skręcaniu skrępowanym względem podłużnej osi elementu $x$ - $x$. Współczynniki $k_{z}$ i $k_{w}$ przyjmują wartość pomiędzy 0,5 (przy zablokowanych stopniach swobody) a 1,0 (przy pełnej swobodzie obrotu i deplanacji) oraz $0,7 \mathrm{w}$ przypadku gdy na jednym końcu pręta są zablokowane deformacje, a na drugim końcu jest pełna swoboda deformacji. W praktyce inżynierskiej powyższe współczynniki najczęściej przyjmuje się po bezpiecznej stronie o wartościach równych $k_{z}=k_{w}=1,0$,

$C_{1}$ - współczynnik równoważnego stałego momentu zależny od obciążenia oraz od współczynników $k_{z}$ i $k_{w}$. Wzory na współczynnik $C_{1}$ dla większości typowych przypadków obciążenia można znaleźć w literaturze, m.in. [1,3-6].

Pozostałe oznaczenia przyjęto zgodnie z [3]. 
Przedstawiony w pracy [2] alternatywny sposób oszacowania sprężystego momentu krytycznego zwichrzenia, bazującego na interakcji symetrycznego i antysymetrycznego składnika momentu krytycznego odniesiono do przypadku obciążenia zginającymi momentami skupionymi na końcach pręta. Podejście przyjęte w pracy [2] można uogólnić do dowolnego schematu obciążenia. Na rys. 1 przedstawiono przykład analizowany w ramach niniejszej pracy.

a)

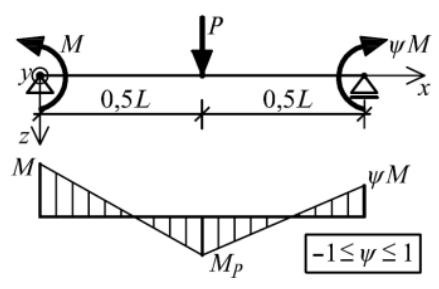

b)

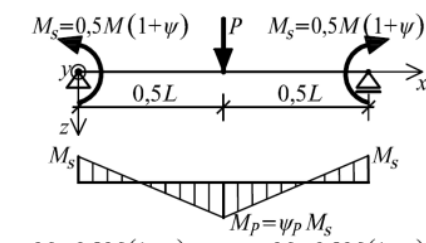

c)

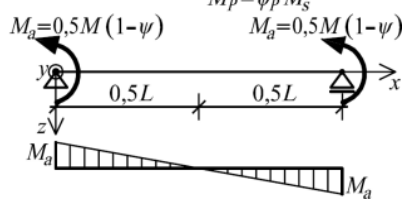

Rys. 1. Rozpatrywany w pracy przykład belki zginanej: a) schemat statyczny, obciążenie i wykres momentu zginającego, b) część symetryczna obciążenia i momentu zginającego, c) część antysymetryczna obciążenia i momentu zginającego

Fig. 1. Example of beam considered in this paper: a) static scheme, loading and bending moment diagram, b) symmetric part of the loading and bending moment diagram, c) anti-symmetric part of the loading and bending moment diagram

Na rys. 2-4 przedstawiono otrzymane na podstawie wyników z programu LTBeamN przebiegi osi odkształconych ( $v$ - przemieszczenia zgodnego z osią $y$, $\theta_{z}=\mathrm{d} v / \mathrm{d} x-$ miary kąta obrotu wokół osi $z, \theta_{x}$ - kąta skręcenia pręta, $\mathrm{d} \theta_{x} / \mathrm{d} x-$ miary deplanacji przekroju pręta) przy dwóch pierwszych postaciach zwichrzenia w odniesieniu do wybranych obciążeń symetrycznych i antysymetrycznych. W przypadku obciążenia symetrycznego momentami skupionymi na końcach pręta $\left(\psi=\psi_{P}=1\right)$ dwie pierwsze postacie zwichrzenia mają podobny przebieg jak pokazane na rys. 2. Współczynniki długości wyboczeniowych wynikających $\mathrm{z}$ postaci zwichrzenia zestawiono $\mathrm{w}$ tabl. 1 . Współczynniki równoważnego momentu odniesione do dwóch pierwszych postaci zwichrzenia dla wybranych szczególnych przypadków obciążenia przedstawiono w tabl. 2.

a)

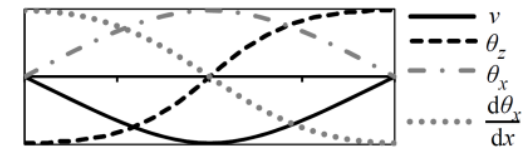

b)

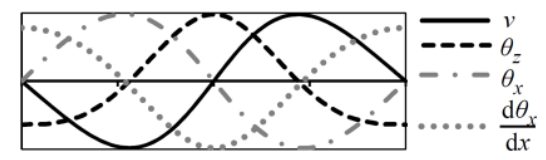

Rys. 2. Postacie wyboczenia przy symetrycznym rozkładzie momentu i schemacie obciążenia nr 2 wg tabeli 2: a) pierwsza, b) druga

Fig. 2. Buckling modes for the symmetric bending moment diagram and No. 2 type of load according to the table 2 : a) the first, b) the second 
a)

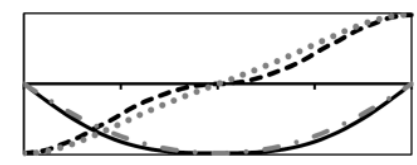

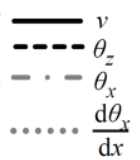

b)

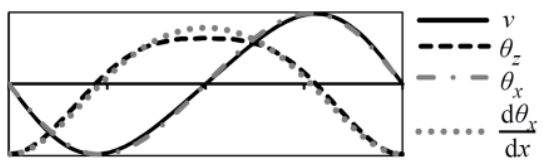

Rys. 3. Postacie wyboczenia przy symetrycznym rozkładzie momentu i schemacie obciążenia nr 3 wg tabeli 2: a) pierwsza, b) druga

Fig. 3. Buckling modes for the symmetric bending moment diagram and No. 3 type of load according to the table 2: a) the first, b) the second

a)

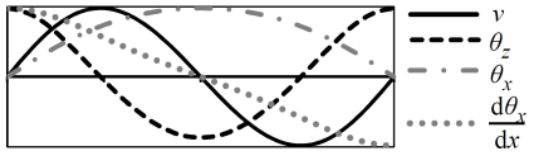

b)

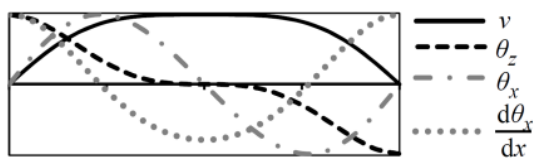

Rys. 4. Postacie wyboczenia przy antysymetrycznym rozkładzie momentu: a) pierwsza, b) druga

Fig. 4. Buckling modes for the anti-symmetric bending moment diagram: a) the first, b) the second

Tabela 1. Współczynniki długości wyboczeniowej związane z postaciami wyboczenia przedstawionymi na rys. 2-4

Table 1. Buckling length factors corresponding to buckling modes of Figs. 2-4

\begin{tabular}{|c|c|c|c|c|}
\hline \multirow{3}{*}{$\begin{array}{l}\text { Nr postaci } \\
\text { zwichrzenia }\end{array}$} & \multicolumn{4}{|c|}{$\begin{array}{l}\text { Współczynniki długości wyboczeniowej w odniesieniu do rozkładu } \\
\text { wykresu momentu zginającego }\end{array}$} \\
\hline & \multicolumn{2}{|c|}{ Wykres symetryczny } & \multicolumn{2}{|c|}{ Wykres antysymetryczny } \\
\hline & $k_{z}=L_{c r, z} / L$ & $k_{w}=L_{c r, w} / L$ & $k_{z}=L_{c r, z} / L$ & $k_{w}=L_{c r, w} / L$ \\
\hline Pierwsza & $k_{z s}=1,0$ & $k_{w s}=1,0$ & $k_{z a}=0,5$ & $k_{w s}=1,0$ \\
\hline Druga & $k_{z a}=0,5$ & $k_{w a}=0,5$ & $k_{z s}=1,0$ & $k_{w a}=0,5$ \\
\hline
\end{tabular}

Tabela 2. Współczynnik $C_{1}$ w odniesieniu do wybranych rozkładów momentów

Table 2. Coefficients $C_{1}$ for particular type of bending moment diagrams

\begin{tabular}{|c|c|c|c|c|}
\hline \multirow[b]{2}{*}{$\mathbf{N r}$} & \multirow[b]{2}{*}{ Schemat obciążenia } & \multirow{2}{*}{$\begin{array}{l}\text { Wykres momentu } \\
\text { zginającego }\end{array}$} & \multicolumn{2}{|c|}{ Współczynnik $C_{1}$} \\
\hline & & & $\begin{array}{c}\text { Pierwsza postać } \\
\text { zwichrzenia }\end{array}$ & $\begin{array}{c}\text { Druga postać } \\
\text { zwichrzenia }\end{array}$ \\
\hline 1 & & 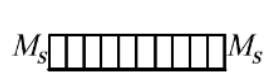 & $C_{1, s}=1,00$ & $C_{1, s a}=1,00$ \\
\hline 2 & $\frac{\downarrow P}{\Delta \vec{\star}_{0,5 L \nmid 0,5 L} \frac{\Delta}{\uparrow}}$ & $M_{M_{P}=0,25 P L}$ & $C_{1, s}=1,35$ & $C_{1, s a}=1,82$ \\
\hline 3 & & $M_{S} \prod$ DI $M_{S}$ & $C_{1, s}=2,64$ & $C_{1, s a}=1,82$ \\
\hline 4 & * & $M_{a} \mathrm{and}$ & $C_{1, a}=1,32$ & $C_{1, a s}=3,62$ \\
\hline
\end{tabular}


Należy zwrócić uwagę, że wartości współczynników długości wyboczeniowych przy antysymetrycznych układach obciążeń innych niż przedstawionych na rys. 1 mogą się różnić od przedstawionych $\mathrm{w}$ tabl. 1 . Zagadnienia te będą przedmiotem przyszłych badań.

Znając rozwiązania elementarnych przypadków zwichrzenia przy symetrycznym i antysymetrycznym układzie obciążeń, sprężysty moment krytyczny zwichrzenia przy dowolnym układzie obciążeń zginających belkę można aproksymować $\mathrm{w}$ postaci:

$$
\frac{M_{\max }}{M_{c r}}=\frac{M_{s, \max }}{M_{c r, s}}+\eta \frac{M_{a, \max }}{M_{c r, a}} \rightarrow M_{c r}=\frac{1}{\frac{1}{M_{c r, s}} \frac{M_{s, \max }}{M_{\text {max }}}+\eta \frac{1}{M_{c r, a}} \frac{M_{a, \text { max }}}{M_{\text {max }}}}
$$

gdzie: $M_{\max }$ - maksymalna bezwzględna wartość z wykresu momentu zginającego w belce,

$M_{s, \max }, M_{a, \max }$ - maksymalna bezwzględna wartość momentu zginającego, odpowiednio w części symetrycznej i antysymetrycznej wykresu momentów,

$\eta$ - funkcja interakcji części symetrycznej i antysymetrycznej momentu krytycznego, zależna od schematu obciążenia,

$M_{c r, s}, M_{c r, a}$ - sprężysty moment krytyczny zwichrzenia odpowiednio przy obciążeniu symetrycznym i antysymetrycznym. W przypadku obciążenia przyłożonego w środku ścinania i pierwszej postaci zwichrzenia:

$$
M_{c r, s}=C_{1, s} i_{C} \sqrt{N_{c r, z s} N_{c r, T s}}, M_{c r, a}=C_{1, a} i_{C} \sqrt{N_{c r, z a} N_{c r, T a}}
$$

gdzie: $N_{c r, z s}, N_{c r, T s}-\mathrm{wg}(2 \mathrm{a}, \mathrm{b})$ po przyjęciu $k_{z}=k_{z s}=1,0$ oraz $k_{w}=k_{w s}=1,0$,

$N_{c r, z a}, N_{c r, T a}-\mathrm{wg}(2 \mathrm{a}, \mathrm{b})$ po przyjęciu $k_{z}=k_{z a}=0,5$ oraz $k_{w}=k_{w s}=1,0$,

$C_{1, s}, C_{1, a}$ - współczynnik równoważnego momentu odpowiednio przy symetrycznym i antysymetrycznym wykresie momentów zginających przyjmowany zgodnie $\mathrm{z}$ tabl. 2 . W przypadku symetrycznego schematu obciążeń, innego od wymienionych w tabl. 2 współczynnik $C_{1, s}$ zaleca się wyznaczać ze wzoru Bijaka [1], który w wielu przypadkach obciążenia lepiej przybliża $M_{c r, s}$ do rozwiązania otrzymanego z MES w porównaniu do analogicznych propozycji podanych w pracach $[5,6]$ :

$$
C_{1, s}=\sqrt{\frac{21 M_{\max }^{2}}{M_{\max }^{2}+6 M_{2}^{2}+8 M_{3}^{2}+6 M_{4}^{2}}}
$$

gdzie: $M_{2}, M_{3}, M_{4}$ - momenty zginające odpowiednio w $1 / 4,1 / 2$ oraz 1/3 rozpiętości belki. 
W przypadku schematu obciążenia przyjętego na rys. 1 i siły $P$ przyłożonej do środka ścinania przekroju (w wypadku przekroju bisymetrycznego pokrywa się ze środkiem ciężkości przekroju), funkcję interakcji części symetrycznej i antysymetrycznej momentu krytycznego $\eta$ można przyjąć w postaci:

$-\operatorname{gdy} M_{s, \max } \geq M_{a, \max }$ :

$$
\eta=\left(\frac{1-\alpha}{2-\alpha}\right)^{n}
$$

gdzie: $\alpha=1-M_{a, \max } / M_{s, \max }$ oraz $0 \leq \alpha \leq 1$,

$$
n=1+\left|\psi_{P}\right| \leq 2
$$

$\psi_{P}-$ współczynnik proporcji momentów przyjmowany zgodnie z rys. 1b,

$-\operatorname{gdy} M_{s, \max } \leq M_{a, \max }$ :

$$
\eta=\left(\frac{1}{2+\alpha}\right)^{n}
$$

gdzie: $\alpha=M_{s, \max } / M_{a, \max }-1$ oraz $-1 \leq \alpha \leq 0$,

$n$ - współczynnik tak jak we wzorze (6a).

Warto zwrócić uwagę, że w przypadku analizowanego przykładu obciążenia (rys. 1), gdy parametr $\psi_{P}=1,0$ (brak siły skupionej $P$ ), funkcje interakcji $\eta$ wg $(6 a, b)$ stają się tożsame, a po przekształceniach można je wyrazić w postaci przedstawionej w pracy [2], tzn. $\eta=0,25(1-\psi)^{2}$, gdzie współczynnik $\psi$ przyjmuje się zgodnie $\mathrm{z}$ rys. $1 \mathrm{a}$.

Na podstawie analizowanego w pracy przykładu (rys. 1), na rys. 4 porównano zaproponowane podejście analityczne szacowania momentu krytycznego z wynikami analiz numerycznych wykonanych przy użyciu programu LTBeamN oraz z wynikami otrzymanymi z konwencjonalnego podejścia analitycznego ze wzoru (1), po przyjęciu współczynnika $C_{1}$ według (5). Z porównania wynika, że praktycznie w całym obszarze rozwiązań zaproponowana alternatywna metoda analityczna jest bliższa wynikom otrzymanym z MES niż podejście konwencjonalne. Wyniki otrzymane ze wzoru (1) są dużo bardziej konserwatywne niż te otrzymane z propozycji (3), szczególnie w odniesieniu do przypadków, gdy dominuje część antysymetryczna momentu zginającego (parametr $\alpha<0$ ). Największe różnice $\mathrm{w}$ całym zakresie parametru $\alpha$ pomiędzy wartościami określonymi wg proponowanego podejścia analitycznego a wzorem konwencjonalnym stwierdzono w przypadkach, gdy parametr $\psi_{P} \in<-1,0 ; 0,0>$. 


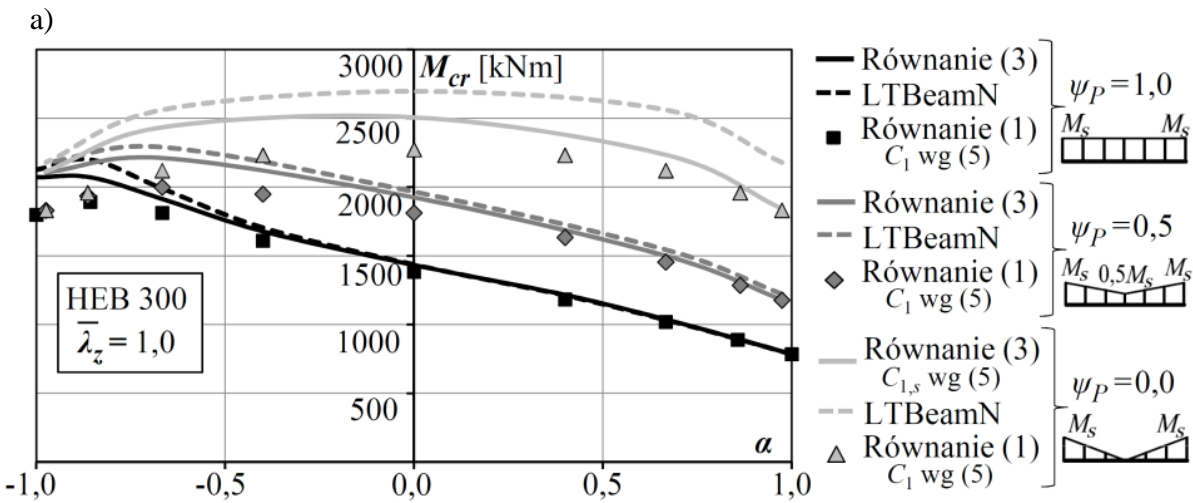

b)
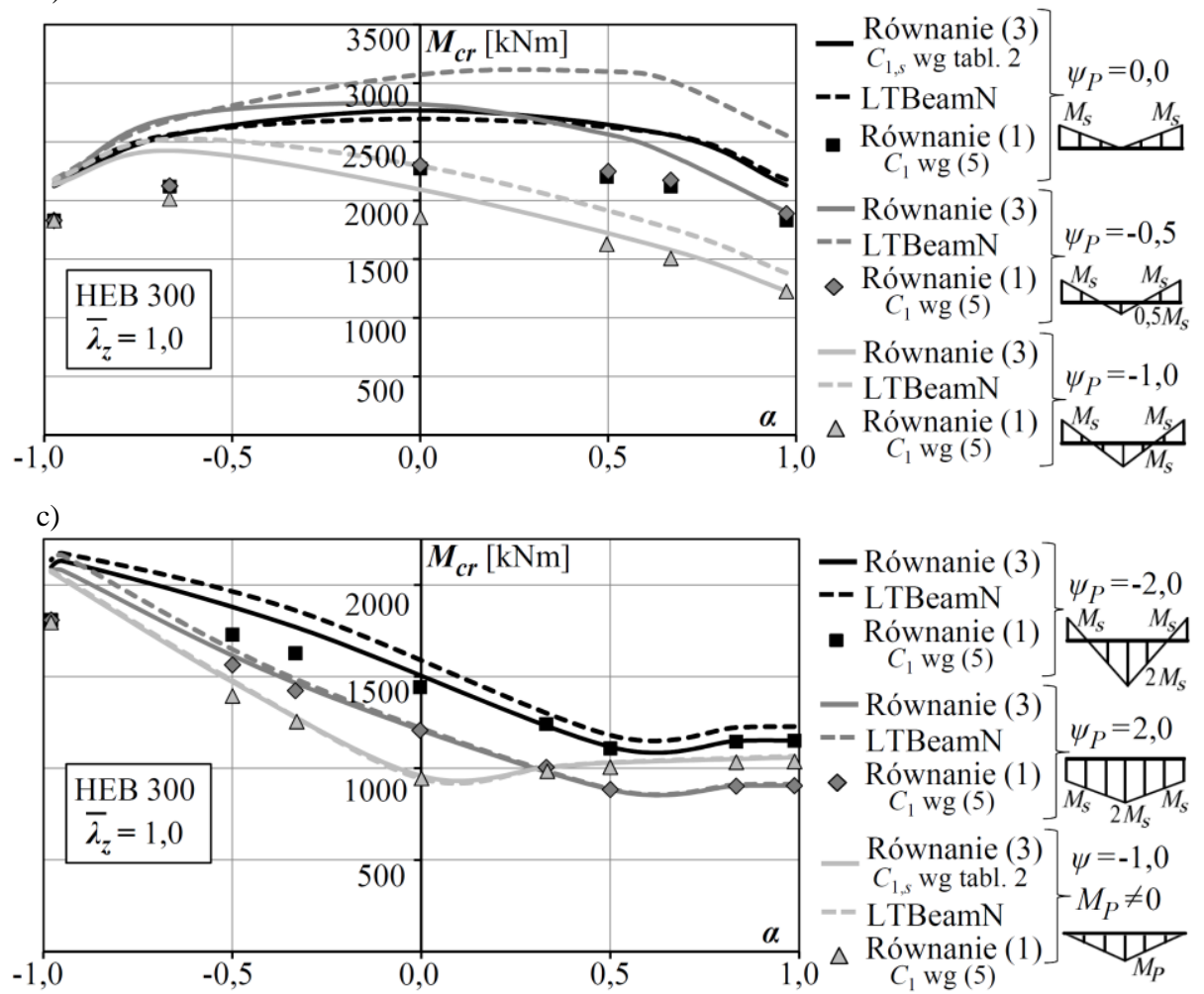

Rys. 5. Porównanie wartości $M_{c r}$ w zależności od parametru $\alpha$ w odniesieniu do belki o wybranej smukłości względnej: a) W przypadku $\psi_{P} \in\langle 0,0 ; 1,0\rangle$, b) w przypadku $\psi_{P} \in\langle-1,0 ; 0,0\rangle$, c) w przypadkach $\psi_{P}<-1,0, \psi_{P}>1,0$ oraz $\psi=-1,0$

Fig. 5. Comparison of results $M_{c r}$ as a function of $\alpha$ for a given beam relative slenderness ratio: a) in case of $\left.\psi_{P} \in\langle 0,0 ; 1,0\rangle, \mathrm{b}\right)$ in case of $\left.\psi_{P} \in\langle-1,0 ; 0,0\rangle, \mathrm{c}\right)$ in cases of $\left.\psi_{P}<-1,0, \psi_{P}\right\rangle 1,0$ and $\psi=-1,0$ 


\title{
3. Podsumowanie
}

Przedstawiono opracowane $\mathrm{w}$ [2] podejście analityczne do wyznaczenia sprężystego momentu krytycznego zwichrzenia stalowych belek o dwuteowym przekroju bisymetrycznym, uogólniając je na przypadki dowolnego przebiegu momentu zginającego. Zaproponowane podejście analityczne porównano na wybranym przykładzie z wynikami symulacji MES i stwierdzono, że przybliża wyniki numeryczne w stopniu lepszym niż analityczne podejście konwencjonalne. W kolejnym etapie badań rozważane będą przypadki dotyczące innych rozkładów momentu zginającego i innych oddziaływań przęsłowych, w tym obciążeń przyłożonych poza środkiem ścinania przekroju.

\section{Literatura}

[1] Bijak R.: Moment krytyczny zwichrzenia niestężonych bisymetrycznych belek dwuteowych podpartych widełkowo. ICMS 2011 Conference, Wrocław 2011.

[2] Giżejowski M., Stachura Z., Uziak J.: Elastic flexural-torsional buckling of beams and beam-columns as a basis for stability design of members with discrete rigid restraints, Proceedings SEMC 2016 Conference, Cape Town 2016 (w druku).

[3] PN-EN 1993-1-1: Eurokod 3 - Projektowanie konstrukcji stalowych. Część 1-1: Reguły ogólne i reguły dla budynków.

[4] Rykaluk K.: Zagadnienia stateczności konstrukcji metalowych, Dolnośląskie Wydawnictwo Edukacyjne, Wrocław 2012.

[5] Serna M.A., López A., Puente I., Yong D.J.: Equivalent uniform moment factors for lateraltorsional buckling of steel members, Journal of Constructional Steel Research, 62, 2006, s. 566-580.

[6] Trahair N.S., Bradford M.A., Nethercot D.A., Gardner L.: The behaviour and design of steel structures to EC3 (4th Edition), Taylor \& Francis, London-New York 2008.

\section{EVALUATION OF ELASTIC LATERAL-TORSIONAL BUCKLING BASED ON THE INTERACTION OF SYMMETRIC AND ANTI- SYMMETRIC LOADING CASES}

\begin{abstract}
S u m m a r y
This paper presents the elastic lateral-buckling instability problem of steel bi-symmetric Isection beams subjected to mono-axial bending about major principal axis. In reference to the beam under moment gradient, an alternative method for a direct determination of the elastic critical moment for lateral-torsional buckling, based on the superposition of the symmetric and antisymmetric buckling modes has been introduced herein. The proposed analytical approach has been compared with the results of numerical simulations and demonstrated on the example of a simple supported beam subjected to bending under support moments and the span load applied at the shear centre of mid-length section of the beam.
\end{abstract}

Keywords: steel I-section, beam, lateral-torsional instability, LBA

Przesłano do redakcji: 07.06.2016 $\mathrm{r}$.

Przyjęto do druku: 30.06 .2016 r.

DOI: $10.7862 / \mathrm{rb} .2016 .43$ 